\title{
Ervas daninhas como hospedeiras alternativas de patógenos causadores do colapso do meloeiro ${ }^{1}$
}

\author{
Weeds as alternative hosts of melon collapse pathogens
}

\author{
Rui Sales Junior ${ }^{2}$, Odaci Fernandes de Oliveira², Érika Valente de Medeiros ${ }^{3}$, Izabel Macedo Guimarães ${ }^{4}$, \\ Kamila Câmara Correia ${ }^{4}$ e Sami Jorge Michereff ${ }^{5 *}$
}

\begin{abstract}
Resumo - O colapso das ramas é uma importante doença do meloeiro (Cucumis melo) no Nordeste brasileiro. Entretanto, pouco se conhece sobre a importância das ervas daninhas como hospedeiras alternativas dos patógenos causadores do colapso dessa doença no meloeiro. Nesta pesquisa, as ervas daninhas prevalentes foram coletadas em quatro áreas de produção de melão no Nordeste brasileiro durante o período, entre duas estações consecutivas de cultivo e os fungos associados com o sistema radicular foram isolados em culturas puras. Foram coletadas ervas daninhas pertencentes a 16 espécies e 11 famílias botânicas. Dentre os fungos causadores de colapso em meloeiro, das raízes das ervas daninhas foram isolados Macrophomina phaseolina e Rhizoctonia solani. O primeiro fungo foi observado em todas as áreas e isolado de 13 espécies de ervas daninhas, nenhuma previamente registrada como hospedeira do fungo, enquanto o segundo foi detectado apenas em uma espécie botânica e uma área de cultivo. Portanto, o controle das ervas daninhas na entressafra é essencial para o sucesso no manejo do colapso das ramas do meloeiro quando $M$. phaseolina predomina entre os agentes causais.
\end{abstract}

Palavras-chave - Cucumis melo. Macrophomina phaseolina. Rhizoctonia solani. Patógenos radiculares.

\begin{abstract}
The vine collapse is an important melon (Cucumis melo) disease in Brazil and worldwide. Little is known about the importance of weeds as alternative host of melon collapse pathogens. During this research, the prevalent weeds were collected in four fields of melon production in the Brazilian Northeast during the period between two consecutive growing seasons and the fungi associated with the root systems were isolated in pure culture. The weeds collected belonged to 16 species and 11 botanical families. Among the fungi causing melon vine collapse, from weed roots were isolated Macrophomina phaseolina and Rhizoctonia solani. The first fungi was observed in all fields and isolated from 13 weed species, any previously registered as fungi host, while the second was detected only in a single botanical species and one field. Therefore, weed control in between melon growing seasons is essential for success in the management of the vine collapse of the melon when M. phaseolina predominates among the possible root pathogens.
\end{abstract}

Key words - Cucumis melo. Macrophomina phaseolina. Rhizoctonia solani. Root pathogens. Colonization.

\footnotetext{
* Autor para correspondência

'Recebido para publicação em 09/06/2010; aprovado em 07/07/2011

Pesquisa financiada pelo CNPq

${ }^{2}$ Departamento de Ciências Vegetais/UFERSA, Caixa Postal 137, Mossoró-RN, Brasil, 59.625-900, ruisales@ufersa.edu.br

${ }^{3}$ Unidade Acadêmica de Garanhuns, UAG/UFRPE, Av. Bom Pastor, s/n, Garanhuns-PE, Brasil, 55.292-270, evmbio@gmail.com

${ }^{4}$ Pós-Graduanda em Fitopatologia/UFRPE, Av. Dom Manoel de Medeiros, s/n, Recife-PE, Brasil, 52.171-900, izabelmguimaraes@hotmail.com;

kamilacamarac@gmail.com

${ }^{5}$ Departamento de Agronomia/UFRPE, Av. Dom Manoel de Medeiros, s/n, Recife-PE, Brasil, 52.171-900, sami@depa.ufrpe.br
} 


\section{Introdução}

A região Nordeste é responsável por $92 \%$ da produção brasileira de melão (Cucumis melo L.) (IBGE, 2010), mas o colapso das ramas vem se destacando como a doença responsável por limitar seriamente a produção (ANDRADE et al., 2005; MARINHO et al., 2002; SALES JUNIOR et al., 2007; SANTOS et al., 2000). Essa doença se expressa com maior intensidade no período quente e seco do ano, que no Nordeste brasileiro compreende os meses de agosto a dezembro (GUIMARÃES et al., 2008). O colapso é decorrente do desequilíbrio hídrico entre o sistema radicular e a parte aérea da planta, principalmente no estádio próximo à colheita, devido o apodrecimento do sistema radicular (GARCÍA-JIMÉNEZ et al., 2000).

Inúmeros agentes patogênicos podem causar $o$ colapso das ramas, que atuam de forma isolada ou em conjunto (AEGERTER et al., 2000; BELTRÁN et al., 2005; BRUTON, 1998; GARCÍA-JIMÉNEZ et al., 2000). Nas áreas de produção dos estados do Rio Grande do Norte e do Ceará, vários fungos associados às raízes de meloeiro podem causar o colapso de ramas, com destaque para Monosporascus cannonballus Pollack et Uecker, Macrophomina phaseolina Tassi (Goid.), Fusarium solani (Mart.) Sacc. e Rhizoctonia solani Kühn (ANDRADE et al., 2005; MARINHO et al., 2002).

Não obstante, apesar do grande número de artigos sobre a etiologia do colapso de ramas em meloeiro (AEGERTER et al., 2000; ANDRADE et al., 2005; BELTRÁN et al., 2006; BRUTON, 1998; CHILOSI et al., 2008; GARCÍA-JIMÉNEZ et al., 2000; MARINHO et al., 2002), pouco se conhece sobre a importância das ervas daninhas como hospedeiras naturais ou multiplicadoras de inóculo dos patógenos nas áreas de produção, principalmente no período da entressafra. Cabe ressaltar que a produção de melão no Nordeste brasileiro se concentra no segundo semestre do ano, motivo pelo qual no semestre subseqüente as ervas daninhas colonizam todas as áreas anteriormente cultivadas com essa cucurbitácea, aproveitando a fertilidade remanescente do solo e a abundante precipitação pluviométrica. Nesse contexto, este trabalho teve como objetivo avaliar a ocorrência de ervas daninhas como hospedeiras alternativas dos principais fungos causadores de colapso de ramas do meloeiro em áreas produtoras no Nordeste brasileiro.

\section{Material e métodos}

O estudo foi realizado em quatro áreas de produção de melão com histórico de elevada incidência de colapso de ramas em safras anteriores. Duas áreas eram situadas no estado do Rio Grande do Norte, nos municípios de Baraúna (Ba) $\left(05^{\circ} 03^{\prime} 25,1^{\prime \prime} \mathrm{S}\right.$ e $\left.37^{\circ} 39^{\prime} 82,2^{\prime \prime} \mathrm{W}\right)$ e Mossoró (Mo) $\left(05^{\circ} 02^{\prime} 03,7^{\prime}, \mathrm{S}\right.$ e $\left.37^{\circ} 22^{\prime} 57,1^{\prime}, \mathrm{W}\right)$, e duas áreas no estado do Ceará, nos municípios de Icapuí $\left(04^{\circ} 51^{\prime} 26,1^{\prime}\right.$ ' S e 37 $\left.21^{\prime} 23,6^{\prime}, \mathrm{W}\right)$ e Quixeré $\left(05^{\circ} 04^{\prime} 35,76^{\prime}\right.$ ' $\mathrm{S}$ e $37^{\circ} 48^{\prime} 58,0$ ' ' W). No período de 18 de dezembro de 2004 a 15 de fevereiro de 2005 foram efetuadas coletas das principais ervas daninhas prevalentes nas áreas de produção. Em cada área foram coletadas 10 plantas de cada espécie botânica, incluindo o máximo do sistema radicular. Após a identificação botânica, a parte aérea das plantas foi eliminada e o sistema radicular cuidadosamente limpo em água corrente, para eliminação dos resíduos de terra aderidos. Após a secagem, foram efetuadas observações do sistema radicular das plantas mediante a utilização de microscópio estereoscópio a 40x no intuito de verificar a presença de estruturas de frutificações de fungos. Posteriormente, as raízes foram desinfetadas em solução de cloro ativo a $1,5 \%$ durante $1 \mathrm{~min}$. e enxaguadas em duas lavagens em água estéril, para retirar o excesso de cloro. Fragmentos de raízes, em total de sete, foram semeados em placas Petri com meio de cultura batata-dextrose-àgar (BDA), suplementado com estreptomicina (500 ppm). Foram efetuados 35 pontos de isolamento por espécie botânica amostrada e as placas incubadas em estufa tipo BOD à temperatura de $25 \pm 1{ }^{\circ} \mathrm{C}$ e fotoperíodo de 12 horas, durante 5-7 dias. Nos casos em que houve crescimento fúngico, fragmentos das colônias foram repicados para placas com meio BDA, visando a obtenção de culturas puras para posterior identificação.

\section{Resultados e discussão}

Nos campos de produção de melão foram coletadas ervas daninhas pertencentes a 16 espécies e 11 famílias botânicas (TAB. 1). Dentre os fungos causadores de colapso em meloeiro, nas raízes das ervas daninhas foram constatados M. phaseolina e $R$. solani, sendo o primeiro registrado em todas as áreas e isolado de 13 espécies pertencentes a 10 famílias botânicas (TAB. 1), enquanto o segundo foi detectado apenas em Senna obtusifolia (L.) Irwin \& Barneby, da família Leguminoseae, em uma área (Quixeré, CE).

O fungo M. phaseolina é habitante do solo e apresenta extensa gama de hospedeiras, sendo patogênico a mais de 680 espécies botânicas (FARR et al., 2010), mas nenhuma das 13 espécies de ervas daninhas dos campos de produção de melão do Nordeste brasileiro tinha sido registrada previamente como hospedeira desse fungo, constituindo, portanto, o primeiro registro dessas novas hospedeiras em nível mundial. 
Tabela 1 - Isolamento de Macrophomina phaseolina de raízes de ervas daninhas prevalentes em áreas de produção de melão localizadas nos estados do Rio Grande do Norte e Ceará

\begin{tabular}{|c|c|c|c|c|c|}
\hline \multirow{2}{*}{ Erva daninha } & \multirow{2}{*}{ Família } & \multicolumn{4}{|c|}{ Local de coleta $^{1}$} \\
\hline & & $\mathrm{Ba}$ & Mo & Ic & $\mathrm{Qu}$ \\
\hline Amaranthus viridis $\mathrm{L}$. & Amaranthaceae & - & - & $+* *$ & + \\
\hline Heliotropium sp. & Boraginaceae & - & - & - & - \\
\hline Merremia aegyptia (L.) Urb. & Convolvulaceae & - & - & + & + \\
\hline Ipomoea asarifolia Roem. et Schult. & Convolvulaceae & - & + & - & + \\
\hline Cyperus rotundus $\mathrm{L}$. & Cyperaceae & - & - & + & - \\
\hline Digitaria sanguinalis (L.) Scop. & Gramineae & + & - & + & - \\
\hline Dactyloctenium aegyptium (L.) Beauv. & Gramineae & - & - & + & - \\
\hline Echinochloa crusgalli (L.) Beauv. & Gramineae & - & - & - & - \\
\hline Senna uniflora (Mill.) Irwin et Barneby & Leguminoseae & + & - & - & - \\
\hline Senna obtusifolia (L.) Irwin \& Barneby & Leguminoseae & + & - & - & - \\
\hline Sida cordifolia $\mathrm{L}$. & Malvaceae & - & - & - & - \\
\hline Malva sylvestris $\mathrm{L}$. & Malvaceae & - & + & - & - \\
\hline Mollugo verticillata $\mathrm{L}$. & Molluginaceae & - & - & + & - \\
\hline Portulaca oleracea $\mathrm{L}$. & Portulacaceae & - & - & + & + \\
\hline Borreria verticillata $\mathrm{G}$. Mey & Rubiaceae & - & - & + & - \\
\hline Waltheria indica $\mathrm{L}$. & Sterculiaceae & + & - & - & - \\
\hline
\end{tabular}

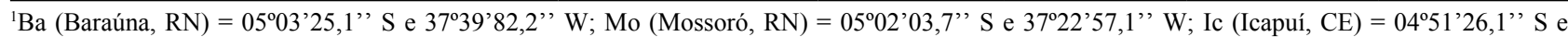
$37^{\circ} 21^{\prime} 23,6$ ' W; Qu (Quixeré, CE) $=05^{\circ} 04^{\prime} 35,76^{\prime \prime}$ S e $37^{\circ} 48^{\prime} 58,0^{\prime \prime}$ W; ** (+) = isolamento positivo; (-) = isolamento negativo

Dentre as espécies hospedeiras de M. phaseolina, o sorgo (Sorghum bicolor L.) é uma das principais culturas adotadas para rotação com o meloeiro no Nordeste brasileiro, principalmente no período da entressafra. Este fato é preocupante, se considerarmos que M. phaseolina foi isolada de duas espécies de plantas da mesma família do sorgo, Digitaria sanguinalis (L.) Scop. e Dactyloctenium aegyptium (L.) Beauv. (TAB. 1).

O fungo $R$. solani é habitante do solo, com elevada capacidade de competição saprofítica e ampla gama de hospedeiros (CUBETA; VILGALYS, 1997; FARR et al., 2010), sendo freqüentemente encontrado parasitando raízes de meloeiro com sintomas de colapso (AEGERTER et al., 2000). No entanto, em estudo de prospecção de patógenos associados a raízes de meloeiro com sintomas de colapso realizado no Nordeste brasileiro (ANDRADE et al., 2005), $R$. solani apresentou baixa prevalência $(40 \%)$ e reduzida freqüência de isolamento (até 18\%), quando comparado ao verificado para $M$. phaseolina, que apresentou prevalência de $100 \%$ e freqüência de isolamento de até
$60 \%$. Apesar de $R$. solani ter sido isolado de apenas uma espécie de erva daninha da família Leguminoseae, o resultado indica que a rotação de culturas com plantas desta família, como caupi (Vigna unguiculata (L.) Walp.), pode resultar em aumento do inóculo no solo e contribuir para o insucesso no cultivo de meloeiro.

Em nenhuma das raízes das ervas daninhas analisadas foi constatada a presença de $M$. cannonballus e $F$. solani, indicando que esses fungos possuem outras estratégias preferenciais de perpetuação entre as safras de melão que não a colonização de ervas daninhas, tendo em vista que são freqüentemente associados ao colapso na região em que o estudo foi realizado (ANDRADE et al., 2005; MARINHO et al., 2002).

Esse estudo evidenciou a importância das ervas daninhas como hospedeiras alternativas para M. phaseolina nos períodos de entressafra da cultura do meloeiro no Nordeste brasileiro, considerando a detecção em todas as áreas amostradas e a amplitude das espécies e famílias botânicas das quais foi isolado. 


\section{Conclusões}

1. O fungo Macrophomina phaseolina foi registrado em ervas daninhas de todas as áreas e isolado de 13 espécies pertencentes a 10 famílias botânicas;

2. O controle das ervas daninhas na entressafra é essencial para o sucesso no manejo do declínio de ramas do meloeiro quando $M$. phaseolina predomina entre os agentes causais.

\section{Agradecimentos}

Os autores agradecem ao Conselho Nacional de Desenvolvimento Científico e Tecnológico (CNPq) pela concessão de recursos para a realização desse trabalho.

\section{Referências}

AEGERTER, B. J. et al. Occurrence and pathogenicity of fungi associated with melon root rot and vine decline in California. Plant Disease, v. 84, n. 03, p. 224-230, 2000.

ANDRADE, D. E. G. T. et al. Freqüência de fungos associados ao colapso do meloeiro e relação com características físicas, químicas e microbiológicas dos solos. Summa Phytopathologica, v. 31, n. 04, p. 326-331, 2005.

BELTRÁN, R. et al. Population dynamics of Monosporascus cannonballus ascospores in marsh soils in eastern Spain. European Journal of Plant Pathology, v. 113, n. 03, p. 357-365, 2005.

BELTRÁN, R. et al. Estudio de patogenicidad a melon de hongos del suelo causantes de colapso. Boletin de Sanidad Vegetal Plagas, v. 32, n. 04, p. 695-707, 2006.
BRUTON, B. D. Soilborne diseases in cucurbitaceae: pathogen virulence and host resistance. In: MCCreight, J. (Ed.) Cucurbitaceae '98. Alexandria: International Society for Horticultural Science, 1998. p. 143-166.

CHILOSI, G. et al. 2008. Fungi associated with root rot and collapse of melon in Italy. EPPO Bulletin, v. 38, n. 01, p. 147-154, 2008.

CUBETA, M. A.; VILGALYS, R. Population biology of the Rhizoctonia solani complex. Phytopathology, v. 87, n. 04, p. 480-484, 1997.

FARR, D. F. et al. Fungus-host distribution database. Disponível em: <http://nt.ars-grin.gov/fungaldatabases/ fungushost/fungushost.cfm>. Acesso em: 02 jun. 2010.

GARCÍA-JIMÉNEZ, J. et al. Fungal pathogens associated with melon plants collapse in Spain. EPPO Bulletin, v. 30, n. 20, p. 169-173, 2000.

GUIMARÃES, I. M. et al. Efeito de fluazinam no controle Monosporascus cannonballus, agente causal do declínio de ramas em meloeiro. Revista Caatinga, v. 21, n. 04, p.147-153, 2008.

INSTITUTO BRASILEIRO DE GEOGRAFIA E ESTATÍSTICA (IBGE). SIDRA 97: Sistema IBGE de Recuperação Automática. Rio de Janeiro, 2010. Disponível em: <http://www.sidra.ibge.gov.br/bda/agric $>$. Acesso em: 01 jun. 2010.

MARINHO, R. E. M. et al. Identificação da micoflora associada a raízes de meloeiro nos estados do Rio Grande do Norte e Ceará. Revista Caatinga, v. 15, n. 01, p. 25-28, 2002.

SALES JÚNIOR, R. et al. Controle biológico de Monosporascus cannonballus com Chaetomium. Fitopatologia Brasileira, v. 32, n. 01, p. 70-74, 2007.

SANTOS, A. A. et al. Doenças do meloeiro em áreas irrigadas no estado do Ceará. Fortaleza: EMBRAPA Agroindustrial Tropical, 2000. 11 p. (Boletim de Pesquisa, 35). 